\title{
Use of a Holistic Design and Manufacturing Approach to Implement Optimized Additively Manufactured Mould Inserts for the Production of Injection-Moulded Thermoplastics
}

\author{
Loucas Papadakis ${ }^{1, *(\mathbb{D} \text {, Stelios Avraam }}{ }^{2}$, Demetris Photiou ${ }^{2}$, Simona Masurtschak ${ }^{3}$ and \\ Juan Carlos Pereira Falcón ${ }^{3}$ (D) \\ 1 Department of Mechanical Engineering, Frederick Research Center, 1303 Nicosia, Cyprus \\ 2 Simlead Ltd., 2038 Nicosia, Cyprus; s.avraam@simlead.eu (S.A.); d.photiou@simlead.eu (D.P.) \\ 3 LORTEK Technological Centre, Basque Research and Technology Alliance (BRTA), 20240 Ordizia, Spain; \\ smasurtschak@lortek.es (S.M.); jcpereira@lortek.es (J.C.P.F.) \\ * Correspondence: 1.papadakis@frederick.ac.cy
}

Received: 26 September 2020; Accepted: 22 October 2020; Published: 24 October 2020

check for updates

\begin{abstract}
Injection moulding is one the most familiar processes for manufacturing of plastic parts by injecting molten thermoplastic polymers into a metallic mould. The cycle time of this process consists of the phases of injection, packing, cooling, and ejection of the final product. Shortening of cycle time is a key consideration to increase productivity. Therefore, in this manuscript the adoption of additively manufactured mould inserts with conformal cooling channels by means of selective laser melting (SLM) with the aim to reduce process cycles is presented. The design and manufacture of a mould insert with conformal cooling channels for producing pressure fitting thermoplastic parts is described. Numerical analysis of the injection process and simulation of shape distortions after SLM were conducted providing useful results for the design and manufacture of the mould insert. The results of the numerical analyses are compared with experimental 3D geometrical data of the additively manufactured mould insert. Temperature measurements during the real injection moulding process demonstrating promising findings. The adoption of the introduced method for the series production of injection moulded thermoplastics proves a shortening of cycle times of up to $32 \%$ and a final product shape quality improvement of up to $77 \%$ when using mould inserts with conformal cooling channels over the conventional mould inserts.
\end{abstract}

Keywords: conformal cooling channels; design for additive manufacturing; selective laser melting; injection moulding of plastic parts; simulation of shape distortions; process simulation of injection moulding

\section{Introduction}

Additive manufacturing (AM) processes have recently gained immense importance in producing industries especially in sectors where high quality and shape accuracy is demanded for low-volume manufacturing or individualized products [1,2]. Laser-based powder-bed fusion (L-PBF) and in particular selective laser melting (SLM) are able to provide metallic products of almost unlimited complexity with mechanical and fatigue behavior similar to bulk material. These advantages make SLM an ideal solution for the fabrication of moulds [3]. Furthermore, the high accuracy and flexibility of SLM can be utilized in order to create optimized dense patterns for cooling channels inside mould inserts approximating the form of the product. During the design of such cooling channels, certain SLM 
process-related restrictions such as overhanging geometries and use of support structures need to be addressed [4].

An important technical aspect is the adequate selection of the material for the moulds. Maraging stainless steel has been the material of choice in aerospace and tooling sectors due to excellent mechanical properties such as high strength and toughness. In addition, excellent wettability and low reflectivity makes them well suited for L-PBF technology [5]. Maraging steels typically present very fine cellular structure due to high cooling rates and rapid solidification during SLM manufacturing. Therefore, maraging steels processed via SLM generally exhibit higher yield strength, tensile strength and hardness compared to wrought counterparts [6].

The process cycle of injection moulding consists of four phases: injection, packing, cooling, and ejection of the final product. Hence, shortening of the cycle time is a key consideration to increase productivity. The total cycle time is dominated by the cooling phase (it can make up to $70 \%$ of the cycle time), i.e., the duration of hot polymer cooling in the cavity [7]. Thus, different cooling methods have been developed by circulating liquids or gases through holes drilled in both the mould and mould inserts. In general, cylindrical and linear channels have been traditionally created but limit the cooling potential. As a result a non-homogeneous heat sink may be generated inside the mould which directly affects the mechanical properties of the product leading to shrinkage, warpage and surface quality issues [8]. Shayfull et al. [9] provide a comprehensive review on the potentials of conforming cooling channels and their importance in reducing the cycle time and improving surface quality of injection-moulded parts acknowledging that further potentials of conforming cooling channels in rapid heat cycle moulding (RHCM) are yet to be explored. Anh [10] presents a thorough state of the art on laser assisted metal rapid tooling processes for the manufacture of forming tools referring in particular to conformal cooling channels in injection moulding. In literature it has been reported that incorporating conformal cooling channels for the injection moulding of plastic component can reduce cycle times by $30-40 \%$ [11]. Due to the recent increasing application of 3D-printing technology in creating conformal cooling channels, various research works have attempted to develop an optimal design for cooling channels [12-14]. Nevertheless, the design and optimization of conformal cooling channels still requires further research since it is very dependent on the related practical application [14].

In this manuscript the potentials of adopting additively manufactured mould inserts with conformal cooling channels by means of SLM are investigated. The design and manufacture of a mould insert with crown conformal cooling channels for the production of pressure fitting thermoplastic parts is presented. While other authors either focus on the design and optimization conformal cooling channels in injection moulds with for particular applications [12-14] or on the cooling effects during injection moulding with different mould materials or hybrid solutions [15], in this work we provide an insight into the holistic design approach of the adoption of additively manufactured mould inserts with conformal cooling channels for the production of injected moulded thermoplastics parts. Hereby, a detailed presentation of the manufacturing process chain of the mould insert including all the necessary process steps for 3D printing by means of SLM, computer numerical control (CNC) machining, heat treatment and electron discharge machining (EDM) is provided. The numerical thermo-mechanical analysis of the injection moulding process including both the transient temperature distribution and the shrinkage of the moulded parts as well as the simulation of shape distortions during SLM are conducted to support design and manufacturing steps [16-18]. Necessary knowledge of the process and product behavior is rendered through conducting numerical analyses in which an optimal design and manufacture of the mould insert is strived for. The results of the numerical analyses have been compared with experimental 3D geometrical data of the additively manufactured mould insert and temperature measurements during actual injection moulding trials in series production. Finally, the injected moulded plastic parts are tested in terms of their shape accuracy and their mechanical performance under tensile and creep loading. The adoption of the introduced mould inserts with conformal cooling channels in the series production of injection-moulded thermoplastics demonstrates 
not only a reduction of process cycle times but a simultaneous improvement of the shape accuracy and the mechanical behavior of the final product.

\section{Design and Manufacturing Chain of Mould Insert with Conformal Cooling Channels}

\subsection{Computer Aided Design (CAD) of Mould Insert and FE Process Model}

As a starting point, the mould insert which has been used for the manufacturing of the injection moulded plastic parts was redesigned in order to maximizing cooling capabilities. Different design variations of the cooling channels were considered with the aim to approach the cavity surface as much as possible with the higher possible density of cooling channels. For this, restrictions and requirements related to the injection moulding and the SLM processes were taken into consideration. The distance of the cooling channels from the cavity surface was set to be greater than $4 \mathrm{~mm}$ for a cooling channel diameter of $8 \mathrm{~mm}$ to ensure a good fatigue resistance of the steel mould for the prescribed injection moulding cycles. These design rules for the cooling channels were selected according to literature [19]. Furthermore, for the form the cooling channels a maximum overhanging angle of $45^{\circ}$ was aimed at in order to abstain from supporting structures inside the cooling channels during SLM fabrication. The SLM process was planned with an additional material of $0.4 \mathrm{~mm}$ to all surfaces of the mould insert CAD geometry. Finally, the complete removal of enclosed non-melted powder in the cooling channels had to be ensured.

Figure 1a shows the mould insert as currently used for the injection moulding process with the traditional cooling channels of marginal cooling potential. A variety of cooling channel configurations depending on the cavity shape are found in the literature $[9,20]$. In Figures $1 b$ and $1 c$ spiral and crown conformal cooling channels are illustrated as possible design solutions. The spiral shape of cooling channels leads to non-uniform cooling of the mould insert and consequently of the cavity surface, i.e., a certain area of the cavity was not covered by cooling channels, due to the predefined position of the cooling inlet and outlet as shown on Figure 1b. In order to comply with aforementioned restrictions, the required positions of cooling inlet and outlet as well as the selection of the cooling channel dimensions were kept. Different channel geometries/configurations can provide optimal solutions in terms of the cross-section dimensions, section size, pitch distance, mould wall to channel centerline distance, etc., as reported by other authors [21]. As the crown configuration of conformal cooling channels offered a symmetrical cooling around the whole surface of the mould insert cavity, this design variant was selected to be further investigated.

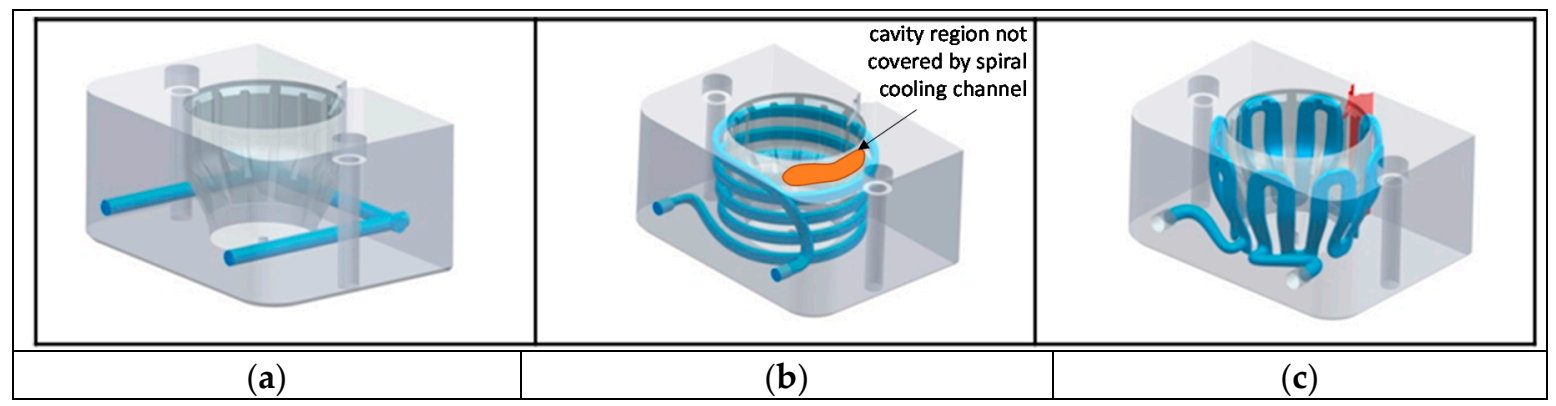

Figure 1. Different configurations of the mould insert cooling channels: (a) current mould insert geometry with conventional cooling channels; (b) Mould insert design variant with spiral conformal cooling channels; (c) mould insert design variant with crown conformal cooling channels.

In order to gain a first insight and to test the cooling improvement potential of the proposed solution, a computational model of the injection moulding process was created based on finite element analysis (FEA). The FE process modeling and simulation was performed with the aid of the software Moldex3D [15-17]. The process parameters, boundaries and material properties used for the transient thermo-mechanical FE model of the injection moulding process can be seen in Table 1 . 
The initial temperature of the melted polymer was set to $230^{\circ} \mathrm{C}$; the cooling medium, i.e., chilled water, inlet temperature was set to $20^{\circ} \mathrm{C}$ and the material properties used were polypropylene (PP) for the injected polymer and maraging steel 1.2709 as the mould insert material. The filling time and injection pressure were selected based on evaluating the fill time used on similar parts and moulds, by trial and error and on existing design of experiments (DOE) data. Hereby, experienced operation of the injection moulding machine foresees an initial filling of the cavity with lower pressure and screw speed with a gradual increase until the part is fully formed. To supplement this, a mould-filling simulation with Moldex3D was performed and the melt front advancement in cavity during the filling process was visualized. From the melt front advancement the filling time can be calculated based on the part shape and volume, the gating system, the injection pressure and the screw speed. By varying the injection pressure and screw speed the filling pattern during moulding was examined and incomplete filling (short-shot), weld lines or air trap locations could be identified. Additionally, the gate contribution could be examined for runner balance and the proper gate location could be identified in order to ensure balance flow and eliminate weld line. The mould-filling simulation with Moldex3D resulted in a filling time of $1.95 \mathrm{~s}$ for the process parameters provided in Table 1.

The mould insert with the conventional cooling channels was compared to the proposed design variant with crown conformal cooling channels. As illustrated in Figure 2, after the completion of the injection phase at $23 \mathrm{~s}$, the temperature on the outer surface of the cap showed a decrease from an average $60^{\circ} \mathrm{C}$ (Figure 2, right) to an average $30^{\circ} \mathrm{C}$ (Figure 2, left) during the final stage of the cooling phase. This was a first evidence of the cooling improvement and process cycle shortening potential by use of the proposed conformal cooling channels' design solution compared to the traditional cooling.

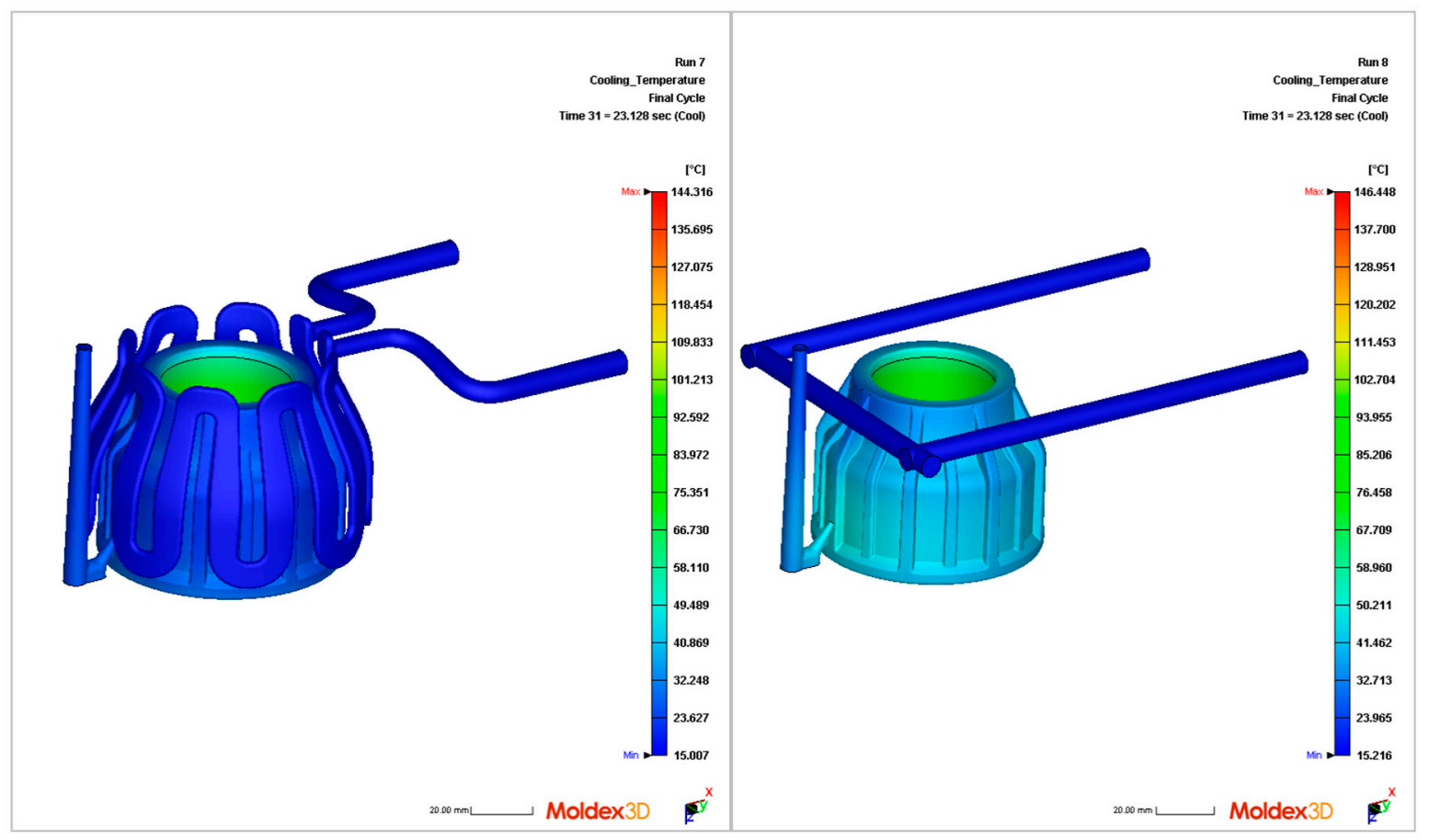

Figure 2. Process temperature reduction in injection moulded cap surface with utilization of crown conformal cooling channels calculated by means of transient thermo-mechanical finite element (FE) model with the aid of the software Moldex3D at 23 s, i.e., completion of injection phase with conformal cooling (left) compared to conventional cooling (right). 
Table 1. Process parameters, boundaries and material properties for the transient thermo-mechanical finite element analysis (FEA) of the injection moulding process with an overall cycle time of $33 \mathrm{~s}$.

\begin{tabular}{|c|c|}
\hline \multicolumn{2}{|c|}{ Process Parameters } \\
\hline Filling Phase & Value/Units \\
\hline Filling time & $2 \mathrm{~s}$ \\
\hline Melt temperature & $230^{\circ} \mathrm{C}$ \\
\hline Max. injection pressure & $80 \mathrm{MPa}$ \\
\hline Screw speed & $21.5 \mathrm{~mm} / \mathrm{s}$ \\
\hline Filing part mass & $60 \mathrm{~g}$ \\
\hline Cooling medium inlet temperature & $20^{\circ} \mathrm{C}$ \\
\hline Packing Phase & Value/Units \\
\hline Packing time & $10 \mathrm{~s}$ \\
\hline Max. packing pressure & $60 \mathrm{MPa}$ \\
\hline Cooling Phase & Value/Units \\
\hline Cooling time & $13 \mathrm{~s}$ \\
\hline Mould open time & $8 \mathrm{~s}$ \\
\hline Air temperature & $30{ }^{\circ} \mathrm{C}$ \\
\hline Mould temperature range & $10-40^{\circ} \mathrm{C}$ \\
\hline Ejection temperature & $112{ }^{\circ} \mathrm{C}$ \\
\hline \multicolumn{2}{|c|}{ Material Properties } \\
\hline Polypropylene (BA160E-8229-01) & Value/Units \\
\hline Density & $900 \mathrm{~kg} / \mathrm{m}^{3}$ \\
\hline Thermal conductivity & $0.22 \mathrm{~W} / \mathrm{mK}$ \\
\hline Specific heat capacity & $1800 \mathrm{~J} / \mathrm{kgK}$ \\
\hline Melt flow rate & $0.3 \mathrm{~g} / 10 \mathrm{~min}$ \\
\hline Tensile modulus & $1300 \mathrm{MPa}$ \\
\hline Shear Modulus & $481 \mathrm{MPa}$ \\
\hline Poisson ratio & 0.392 \\
\hline Tensile strain at yield & $11 \%$ \\
\hline Yield stress & $30 \mathrm{MPa}$ \\
\hline Maraging 300 steel (EN 1.2709) & Value/Units \\
\hline Density & $8000 \mathrm{~kg} / \mathrm{m}^{3}$ \\
\hline Thermal conductivity & $25.3 \mathrm{~W} / \mathrm{mK}$ \\
\hline Specific heat capacity & $3350 \mathrm{~J} / \mathrm{kgK}$ \\
\hline Elastic modulus & $190 \mathrm{GPa}$ \\
\hline Shear Modulus & $73 \mathrm{GPa}$ \\
\hline Poisson ratio & 0.3 \\
\hline Elongation at break (\%) & $5 \%$ \\
\hline Yield strength & $2040 \mathrm{MPa}$ \\
\hline
\end{tabular}

\subsection{Material Selection and Manufacuring Process Chain}

In the context of this work which has received funding within the AMable Project by the European Commission's Horizon 2020, the practical realization and potential for industrial application of the proposed mould insert design was a key element. For this reason a complete manufacturing process chain for utilization of the redesigned mould insert in a real production environment (Technology Readiness Level (TRL) 7) was implemented: (a) the mould insert was 3D printed by means of L-PBF based on the CAD geometry input in standard triangle language (STL) format; (b) the outer contour of the 3D printed mould insert was CNC machined based on technical drawings; (c) the machined injection mould was subjected to a direct aging heat treatment $\left(510{ }^{\circ} \mathrm{C}\right.$ for $\left.6 \mathrm{~h}\right)$ suitable for the hardening of the selected material; (d) the cavity of the mould insert was machined to the final dimensions by means of electron discharged machining (EDM). An overview of the manufacturing process chain of the mould insert is given in Figure 3. For the design of the mould insert geometry, the CAD software NX Siemens was 
used. After the mould insert was 3D printed by means of L-PBF its geometry was 3D scanned with the aid of RangeVision Spectrum 3D Scanning device with automatic turntable. In order to evaluate the shape accuracy of the fabricated mould after SLM, its shape geometry was compared to the target CAD geometry with the aid of the software GOM Inspect Suite 2020. A detailed presentation of the results is provided in Section 2.3.

a) SLM to

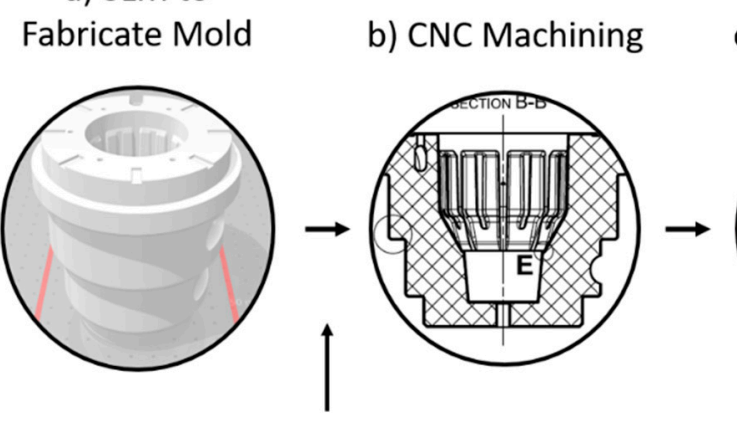

c) Heat Treatment

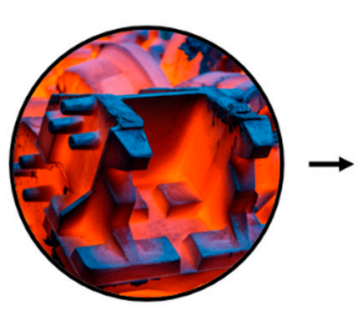

d) EDM Surface Treatment

3D Scan

Figure 3. Manufacturing process chain operations for the mould insert: (a) 3D printing by laser-based powder-bed fusion (L-PBF), (b) CNC machining of outer contour, (c) heat treatment, (d) electron discharged machining (EDM) of the mould insert cavity.

For the production of the mould insert, maraging 300 steel (EN 1.2709) was selected. The reason for choosing this material was the need to use a material to achieve a similar hardness Rockwell $\mathrm{C}$ (HRC 48-50) as the original material (EN 1.2343). Maraging steel (MS) has been widely used for moulds and dies in current production [22] and is commercially available for L-PBF technology [23]. The material is an aged-hardenable martensitic tool steel with exceptional mechanical properties such as high tensile strength ( $\leq 2000 \mathrm{MPa}$ after treatment) and hardness (HRC 56-58 after heat treatment). The expected mechanical properties after heat treatment can be found in Table 3 The high Ni content ensures good corrosion resistance which is favorable for surfaces exposed to cooling fluids, as well as dimensional stability during heat treatment and working at medium to high temperatures. During heat treatment, superior mechanical properties will be obtained due to aging hardening of the microstructure. High carbon tool steels (H13 or M2) which would have been adequate alternatives as well due to their use in conventional tooling and moulding applications, were neglected due to difficulties in processing via powder-bed fusion (PBF) techniques. MS 300 provided a comparable alternative with proven AM stability and keeping of mechanical properties. The powder used in this study was provided by EOS $\mathrm{GmbH}$. The powder has a size distribution of $<63 \mu \mathrm{m}$. The chemical composition range of this powder is given in Table 2 .

Table 2. Chemical composition range of maraging 300 Steel powder (wt.\%). Source: EOS maraging Steel MS1 Data Sheet for EOS M290 400 W machine.

\begin{tabular}{cccccccccccc}
\hline Al & C & Cr & Co & Cu & Mn & Mo & Ni & N & O & Si & Ti \\
\hline $0.05-0.15$ & $<0.03$ & $<0.5$ & $8.5-9.5$ & $<0.5$ & $<0.1$ & $4.5-5.2$ & $17.0-19.0$ & $<0.1$ & $<0.1$ & $<0.1$ & $0.6-0.8$ \\
\hline
\end{tabular}

\subsection{Selective Laser Melting (SLM) Process and Finite Element Analysis (FEA) of Mould Insert Shape Accuracy}

The final mould insert design which is shown in Figure 1c, was optimized based on injection moulding machine settings and restrictions given by the PBF process as discussed in Section 2.1.

Figure 4 presents the evolution of the mould insert CAD geometry until the final printable version. To ensure the removal of non-melted powder in the cooling channels, five escape holes were included on the top side of the mould insert (indicated in red in Figure $4 \mathrm{~b}$ ). After the completion of the manufacturing process, these escape holes could be easily closed off. 


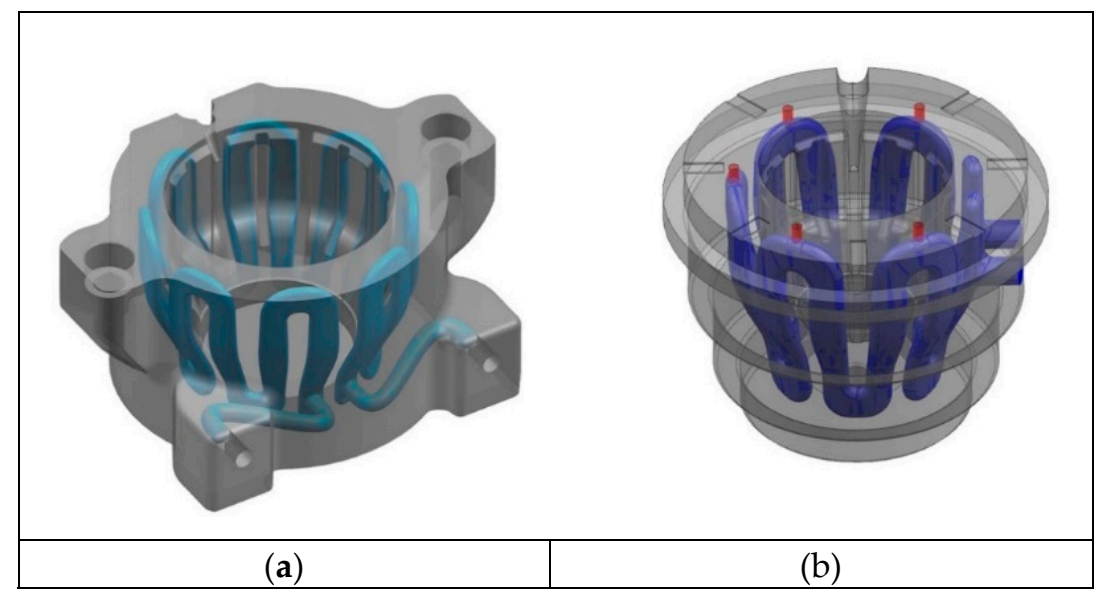

Figure 4. CAD geometry evolution of the mould insert designed with the aid of the CAD software NX Siemens: (a) first design iteration; (b) final CAD geometry including necessary details for SLM process feasibility.

The part was manufactured using L-PBF technology provided by FIT Prototyping GmbH, Germany. For the fabrication of the part a material allowance of $0.4 \mathrm{~mm}$ was added to the 3D CAD file. The reason for this allowance was the required CNC machining of the part after the L-PBF process in order to create the required tooling points for a tight fit in the machine. The mould inserts with a height equal to $68 \mathrm{~mm}$ and a maximum diameter up to $93 \mathrm{~mm}$ were manufactured using an EOS M290 machine with a building area of $250 \mathrm{~mm} \times 250 \mathrm{~mm} \times 325 \mathrm{~mm}$. This machine is equipped with a $400 \mathrm{~W}$ fiber laser and works with a protective atmosphere (inert gas). A process parameter window for the selected material was studied by LORTEK in a previous research work [24]. For the manufacture of the mould insert, the parameter set EOS MS1_040_Performance was used. This set of parameters is a standard set recommended and developed by EOS for maraging steel. The parameter set is not open; hence, the exact processing parameters were not accessible to the authors of the paper. The layer thickness was $50 \mu \mathrm{m}$ and the hatching strategy was stripe-filling.

The orientation of the part within the build platform was selected to minimize supports and distortion risks. Taking advantage of the partial radial symmetry of the part, the part was placed with greater masses and insert of mould on the platform (combined with support structures). The orientation of the part in the machine is visualized in Figure 5. Support structures were utilized to enable the manufacture of the horizontal shoulders with progressively increasing diameter along the build-up direction of the mould insert.

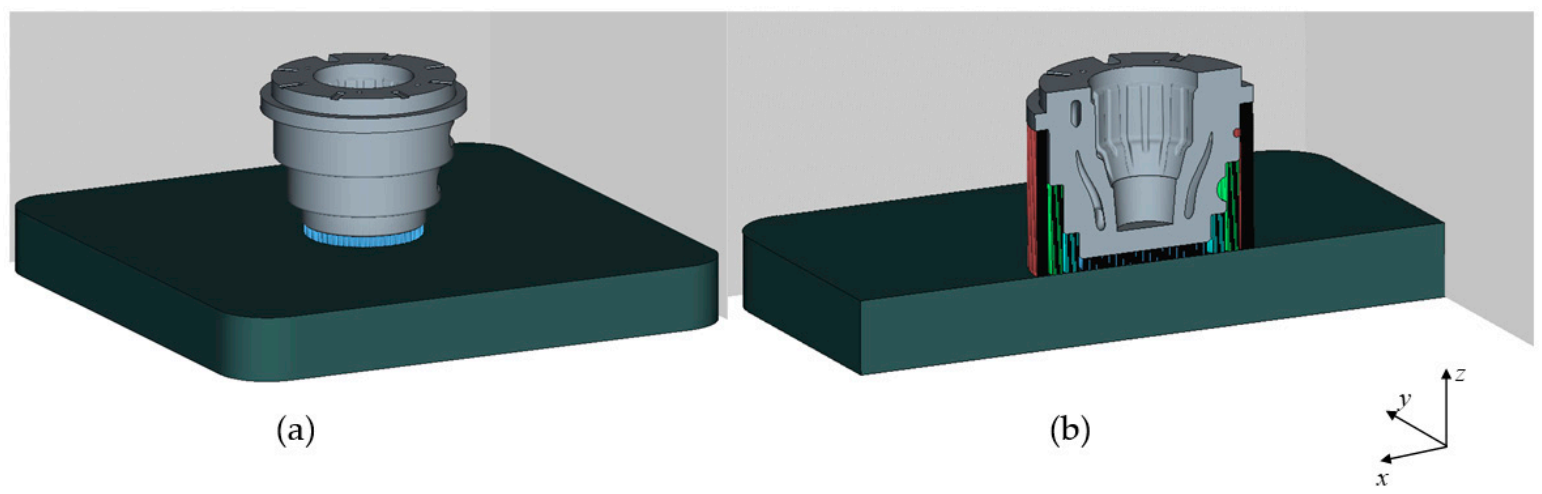

Figure 5. L-PBF machine setting for the fabrication of the mould insert: (a) positioning, orientation and supports on the base plate; (b) support structure definition in the region of the horizontal shoulders with progressively increased diameter. 
The build-up process during L-PBF as well as the removal from the base plate and support structures was modeled and simulated by FEA with the software SIMUFACT [25]. A pure mechanical transient model replicating the processing of 20 real process layers simultaneously in the model was adopted using the method of inherent strains with an element size of $1 \mathrm{~mm}$. The defined values of the inherent strains in the in-plane direction were set to $\varepsilon_{x x}=\varepsilon_{y y}=0.0025$, whereas in the build-up direction a value of $\varepsilon_{\mathrm{zz}}=0.03$ was used. These values were chosen based on experience values from previous experimentation with similar materials and according to knowledge gained from literature [26]. The use of a pure mechanical transient model was chosen over a transient thermo-mechanical FE simulation due to rapid computation times without the use of high-performance computing (HPC) facilities. Fast computation times allow for the computational aid during the development of SLM fabricated products for industrial applications especially for small and middle-size enterprises (SMEs). Such a computation approach helps to identify problematic regions in terms of shape accuracy or residual stress concentration, and thus provides valuable knowledge for the selection of part orientation and support definition in SLM processing due to reasonable computation times $[25,26]$.

Table 3. Heat treatment conditions and mechanical properties for maraging 300 (EN 1.2709) samples tested by LORTEK [27].

\begin{tabular}{ccccccc}
\hline \multirow{2}{*}{$\begin{array}{c}\text { Aging } \\
\text { Temperature }\left({ }^{\circ} \mathrm{C}\right)\end{array}$} & Aging Time (h) & \multicolumn{2}{c}{ Hardness } & Yield Strength \\
\cline { 3 - 4 } & & $\begin{array}{c}\text { Vickers } \\
\text { Number (HVN) }\end{array}$ & $\begin{array}{c}\text { Rockewell } \\
\text { C (HRC) }\end{array}$ & $\begin{array}{c}\text { Ultimate } \\
\text { Tensile } \\
\text { Strength (MPa) }\end{array}$ & $\begin{array}{c}\text { Elongation } \\
\text { at Break (\%) }\end{array}$ \\
\hline 510 & 6 & $620-650$ & $56-58$ & 2040 & 1930 & 5 \\
\hline
\end{tabular}

The additively fabricated mould insert by means of PBF is illustrated in Figure 6. A high degree of quality and accurate detailing of the component are clearly visible including all design features. Figure 7 visualizes the shape deviation normal to surfaces of the 3D scanned real mould insert scanned with the aid of a RangeVision Spectrum 3D Scanning device compared to the ideal CAD geometry. The inspection was performed with the software GOM Inspect Suite 2020. Maximum shape deviation of solely $-0.15 \mathrm{~mm}$ was observed in the outer region of the mould insert, while in the cavity region deviations were only limited to $+0.10 \mathrm{~mm}$. A similar trend was noticed for the final shape of the FE simulated mould insert with shape deviation compared to CAD not exceeding $\pm 0.20 \mathrm{~mm}$ in the outer surfaces and \pm 0.05 in the cavity surface.
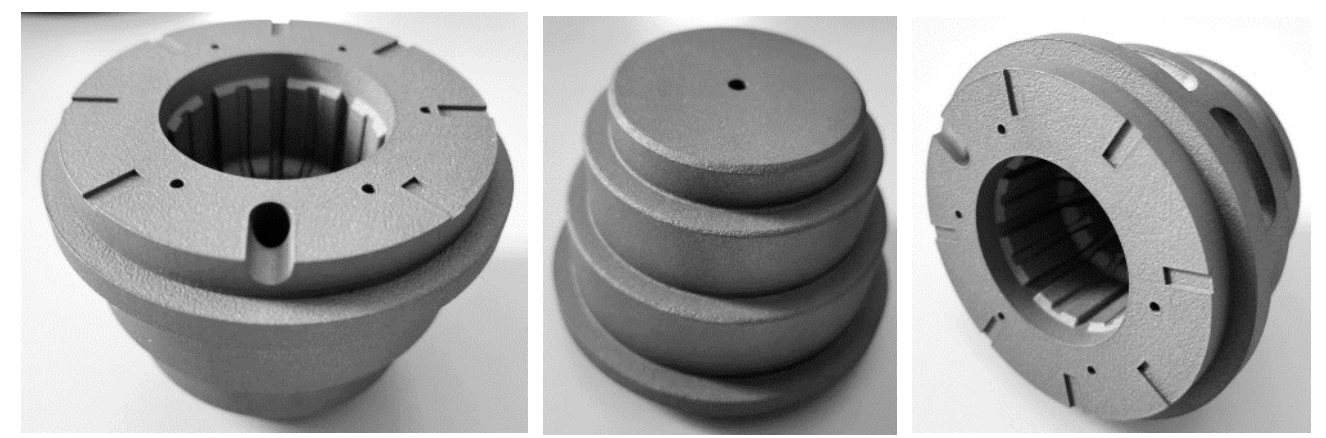

Figure 6. Fabricated mould insert with conformal cooling channels after SLM process including support removal. 


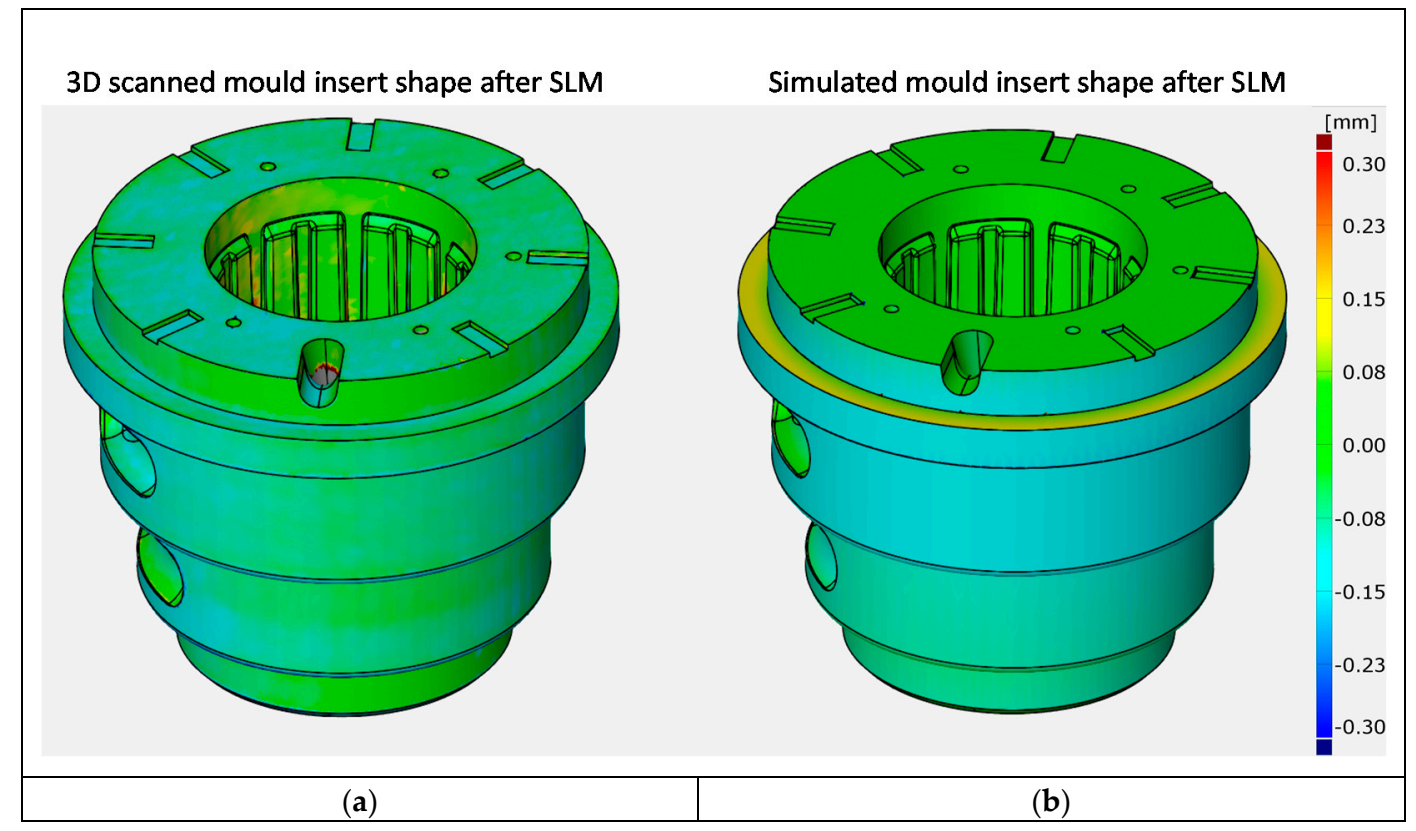

Figure 7. Comparison of the shape accuracy to CAD ideal geometry of the: (a) 3D scanned mould insert fabricated by SLM; (b) simulated mould insert shape by means of FEA with the method of inherent strains after SLM and support removal.

\subsection{Heat Treatment, Mechanical Properties and Final Post-Processing of Mould Insert}

In order to achieve the required dimensions of the mould insert, $\mathrm{CNC}$ machining was carried out on a HASS VF-3 3-axis machine. The previously added material allowance of $0.4 \mathrm{~mm}$ was removed by a special cutting tool (End Mill M16 4 Flutes). Advanced software was used to control the machine tool according to the mould insert specifications with surface roughness $R_{a}=3.2 \mu \mathrm{m}$ and dimensional tolerances of $\pm 0.05 \mathrm{~mm}$. For this purpose, a G-code was created by the NX Siemens Computer Aided Manufacturing (CAM) software. After the CNC machining, heat treatment was carried out in order to obtain the desired hardness of the part. As an appropriate heat treatment, direct artificial ageing was considered [27]. A heating rate of $10^{\circ} \mathrm{C} / \mathrm{min}$ until $510^{\circ} \mathrm{C}$ was applied for $6 \mathrm{~h}$. The chosen cooling method was free cooling inside the furnace until $200^{\circ} \mathrm{C}$. After that free cooling outside the furnace was carried out. The anticipated results of a part undergoing this heat treatment cycle can be seen in Table 2. The hardness of the inserts moulds was measured using a portable hardness tester HARTIP 1500 with a result of $56.6 \mathrm{HRC}$ which satisfies the expected values and the mould insert requirements as set by the end manufacturer.

Figure 8 shows the tensile behavior of samples additively manufactured in the z-building direction using L-PBF with maraging steel 1.2709 powder with subsequent heat treatment at different aging temperatures [27]. It is observed that low temperature ageing up to $510{ }^{\circ} \mathrm{C}$ induced a significant improvement of tensile strength in comparison to the as-built condition. However, the ductility drops from $13 \%$ to $2 \%$ when aging at $480{ }^{\circ} \mathrm{C}$. The reason for this may be the precipitation of fine $\mathrm{Ni}_{3}(\mathrm{Ti}, \mathrm{Mo})$ phase which strengthen the matrix [26]. For this work an ageing temperature of $510^{\circ} \mathrm{C}$ for $6 \mathrm{~h}$ was selected to ensure adequate mechanical properties of the moulds.

In a final step, to achieve the required surface roughness at the mould insert cavity, EDM was performed. The EDM was carried out using an AJAN NEWMAC 50AS200 machine according to the standard set by Verein Deutscher Ingenieure (VDI) 3400 33-36 achieving a surface roughness of $\mathrm{R}_{\mathrm{a}}=4.5 \mu \mathrm{m}$ to $6.3 \mu \mathrm{m}$ and dimensional tolerances of $\pm 0.1 \mathrm{~mm}$. By carrying out EDM, the required surface texture in the cavity of mould insert and dimensional tolerances were obtained. 


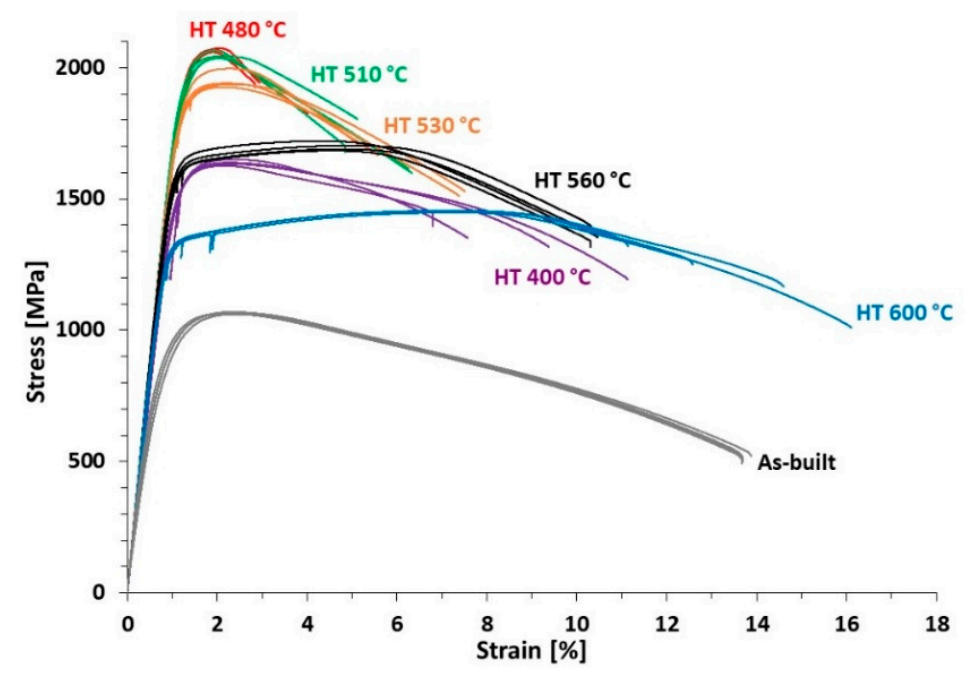

Figure 8. Tensile curves of maraging 300 (EN 1.2709) samples manufactured by SLM in LORTEK (as-built and direct aged with different temperatures for $6 \mathrm{~h}$ ) [27].

\section{Application of Developed Mould Insert for Injection-Moulding Process in Series Production}

\subsection{Injection-Moulding Process Setup}

Upon finalization of the fabrication process, the mould insert was used for the injection-moulding process of a polypropylene fitting cap in series production conditions. The melt temperature is one of the most important factors in injection moulding of polymers: the optimal melt and mould temperatures for the polymer were provided by the material supplier/producer Borealis. The temperatures gradually decreases from the nozzle zone to the zone near the hopper to about $45^{\circ} \mathrm{C}$. To enable better transport of plastic pellets during plasticization the temperatures constitute up to $230^{\circ} \mathrm{C}$ at the nozzle zone: $220^{\circ} \mathrm{C}$ at the front zone, $200^{\circ} \mathrm{C}$ at the middle zone and $185^{\circ} \mathrm{C}$ at the rear zone. Figure 9 illustrates the material feeding process in an injection machine (top left) and the injection mould system (right) which consists of the stationary platen with the mould inserts cavity and the movable platen with the mould thread as currently used in the production at Elysee Irrigation Ltd. The injection process was performed by using alternately conventional and conformal mould inserts in the current injection machine with a 6 series production mould as shown in Figure 6 (bottom left). The existing conventional mould inserts have been used for the past two years in the current production and were manufactured by means of traditional machining operations with the steel EN 1.2343. The injection moulding process parameters used for the FEA of the injection moulding process with conformal cooling result to an overall cycle time of $33 \mathrm{~s}$ and can be found in Table 1. The cycle time for the original conventional cooling mould insert was $48 \mathrm{~s}$. The injection pressure was selected to be as low as possible to reduce part internal stresses. For this reason, different trials were performed by gradually increasing the filling and holding pressure. The quality of the final plastic product was examined until satisfactory results were obtained for a filling pressure of $80 \mathrm{MPa}$ and holding pressure of $60 \mathrm{MPa}$. The finding of a filling pressure was carried out in order to keep the process pressure at the lowest possible level and, thus, prevent unnecessary mould fatigue and damage to the moulded product.

Figure 10 illustrates the fitting assembly for the connection of plastic pipes including all the involved components (left) and a detailed technical drawing of the injection moulded cap (right). The producing company Elysee Irrigation Ltd. applies tolerances for this kind of parts according to DIN16742 of tolerance group TG5 which equals $\pm 0.2 \mathrm{~mm}$ for this part size, i.e., dimensions. 

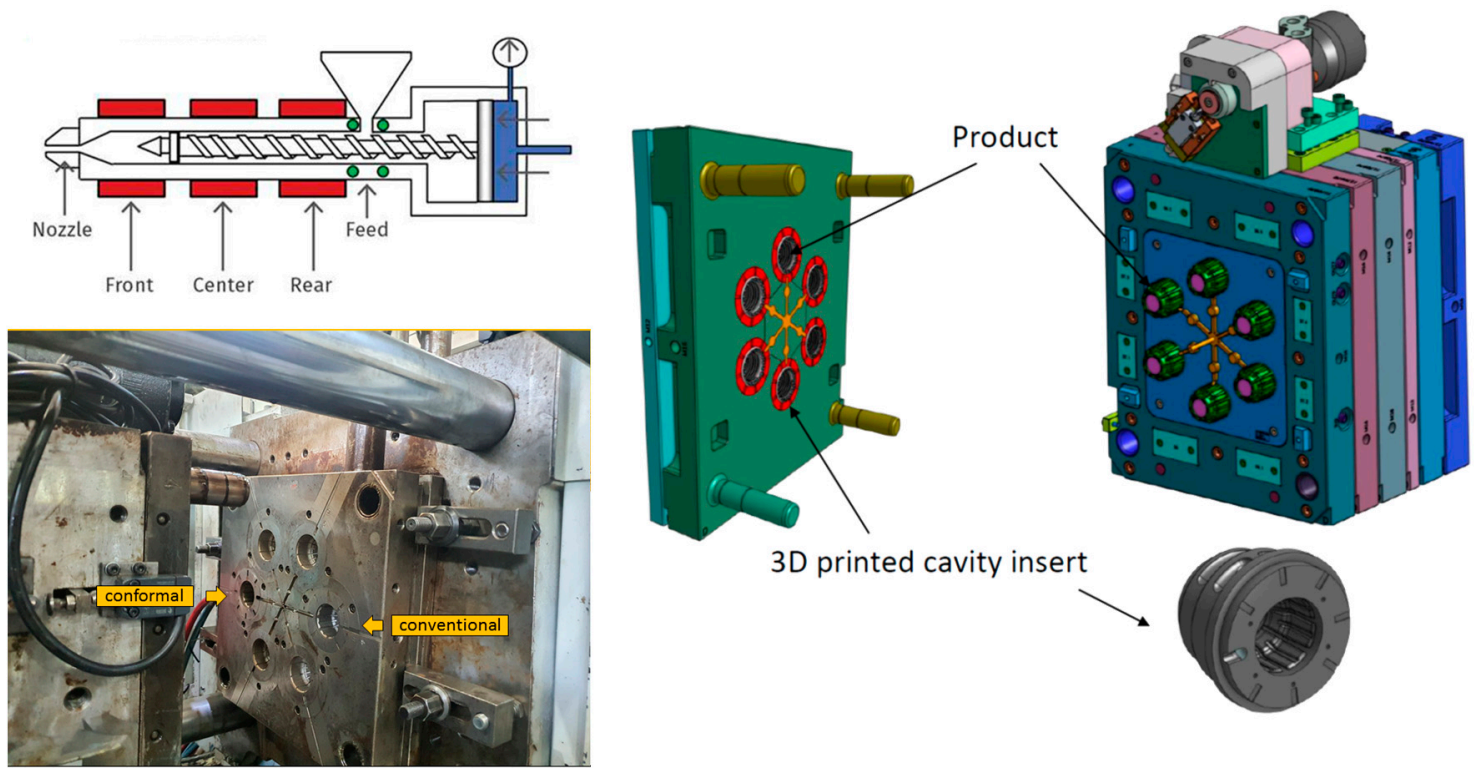

Figure 9. Schematic cross-section view of the feeding process (top left), injection mould system including the stationary platen with mould inserts, polymer products and movable platen with mould threads (right) and injection moulding machine setup with alternate using of conformal and convectional mould inserts on a 6 series production mould as used by Elysee Irrigation Ltd.

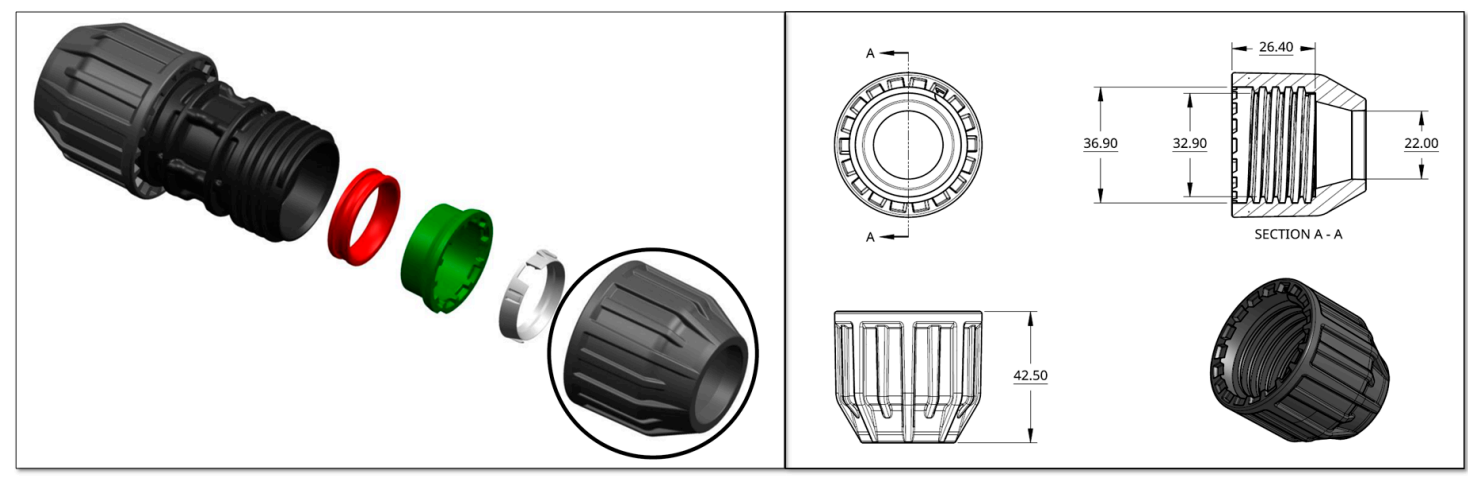

Figure 10. Fitting assembly for the connection of plastic pipes including all the involved components (left) and detailed technical drawing of the produced injection-moulded cap with tolerances according to DIN16742 TG5 (right).

\subsection{Results of Process and Injection-Moulded Product in Comparison to FE Process Model}

\subsubsection{Process Temperatures}

In order to observe the temperature development during the real-time injection-moulding process, the temperatures in the mould insert cavity and on the final plastic product were measured immediately after ejection using a FLIR ${ }^{\circledR}$ handheld infrared thermal camera for both conventional and conformal cooling channels. Measurements were performed on caps produced by the two different mould inserts with conformal and convectional cooling, i.e., 12 measurements for each mould insert type every 5 cycles. The cavity of each mould insert type was measured once every 10 cycles 5 times. The measurement error of the FLIR the thermal camera was $\pm 2 \%$ of reading for ambient temperature $10{ }^{\circ} \mathrm{C}$ to $35^{\circ} \mathrm{C}$. The emissivity $\varepsilon$ was set to 0.8 for the performed measurements based on the FLIR manual suggestion for semi-matt roughened or oxidized metallic surfaces. The same emissivity was used for the measurement of caps due to dark color and semi-matt surface. Calibrating measurements 
were performed for known ambient temperatures prior to experimentation to verify the accuracy of the measurement. The measured average temperatures with standard deviation are shown in Figure 11.

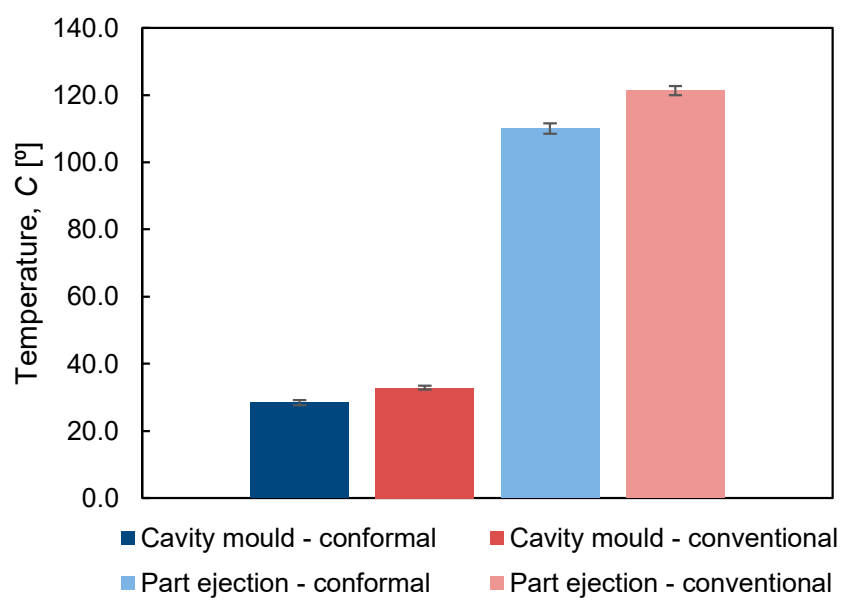

Figure 11. Average temperature measurements with infrared thermal camera immediately after ejection on mould cavity and on part for conformal and convectional cooling.

In the cavity insert an average temperature of $28.4^{\circ} \mathrm{C}$ was recorded in the case of conventional cooling. The mould insert with conformal crown cooling channels demonstrated an average temperature of $32.9^{\circ} \mathrm{C}$ at a similar position for the same instant of time upon ejection (Figure 12). A temperature reduction of $14 \%$ was achieved when using the mould insert with the conformal cooling channels for the same parameter set. The simulation of the injection moulding process by means of FEA as described in Section 2.1 showed a similar trend for the mould insert with conformal cooling with an average calculated temperature on the cavity surface of $36.6^{\circ} \mathrm{C}$. The lower measured temperature compared to the simulation temperature can be explained by the time delay introduced by opening of the moulds during ejection, until the thermal camera can capture the temperature inside the mould insert cavity.
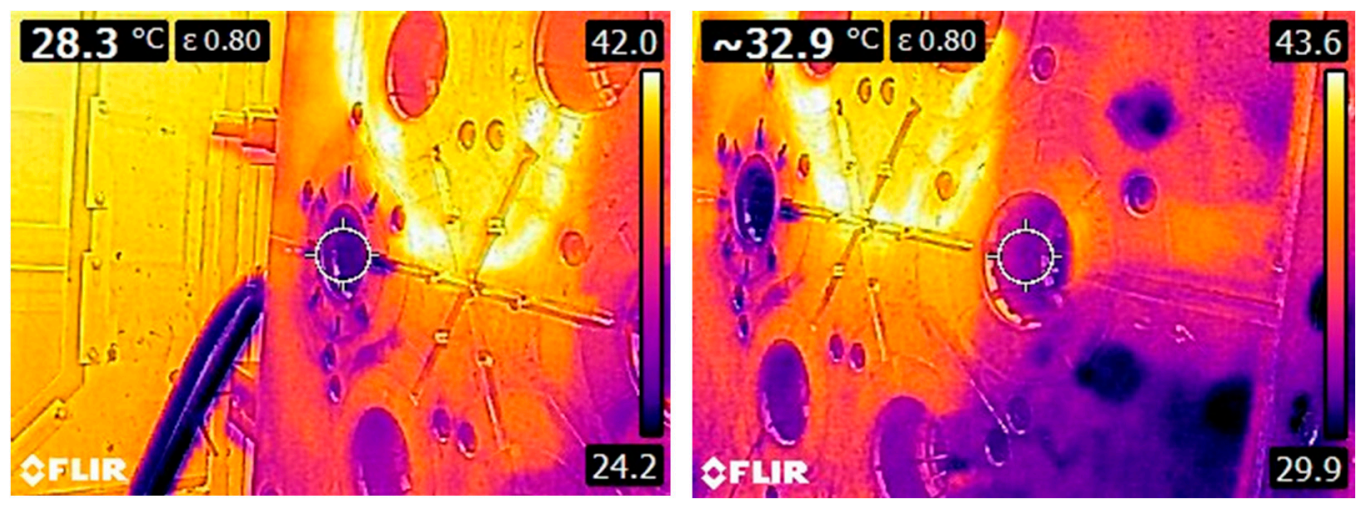

Figure 12. Cont. 


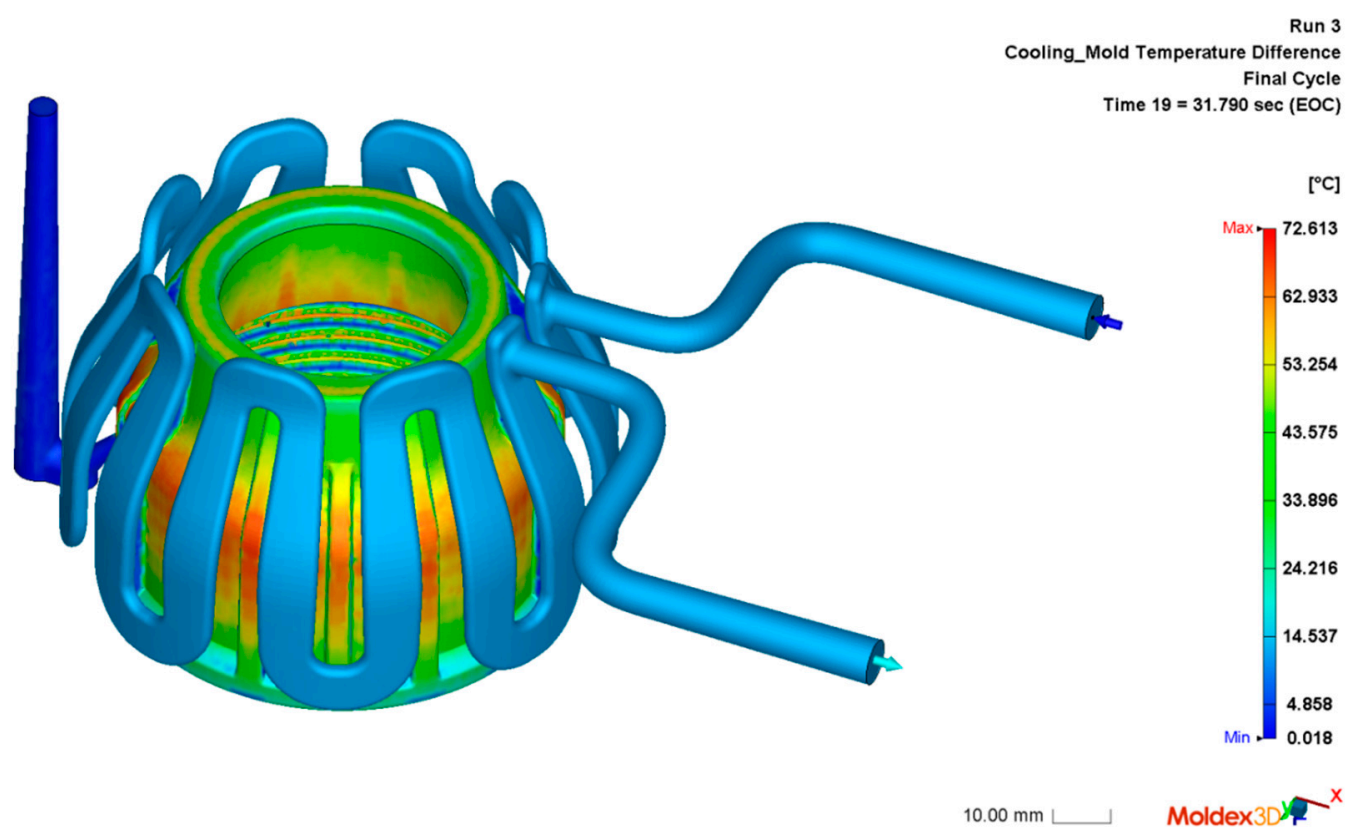

Figure 12. Temperature measurements with infrared thermal camera after ejection demonstrating the temperature reduction in mould insert's cavity when applying conformal cooling (top left) compared to conventional cooling (top right) and simulated temperatures with conformal cooling by means of FEA immediately after ejection with average temperature in the cavity of $36.6^{\circ} \mathrm{C}$ (bottom).

A similar temperature behavior was observed on the plastic caps produced by the two mould insert types. An average temperature of $110.1^{\circ} \mathrm{C}$ was recorded for parts produced with mould inserts with conformal cooling, whereas the use of a mould insert with conventional cooling demonstrated significantly higher average temperatures of $121.4^{\circ} \mathrm{C}$ (Figures 11 and 13 (top)). An approximate temperature reduction of $9 \%$ could be achieved when using conformal cooling channels. A similar trend was calculated by the FE model of the injection-moulding process with conformal cooling with an average temperature of approximately $110^{\circ} \mathrm{C}$ on the cap outer surface (Figure 13 (bottom)).

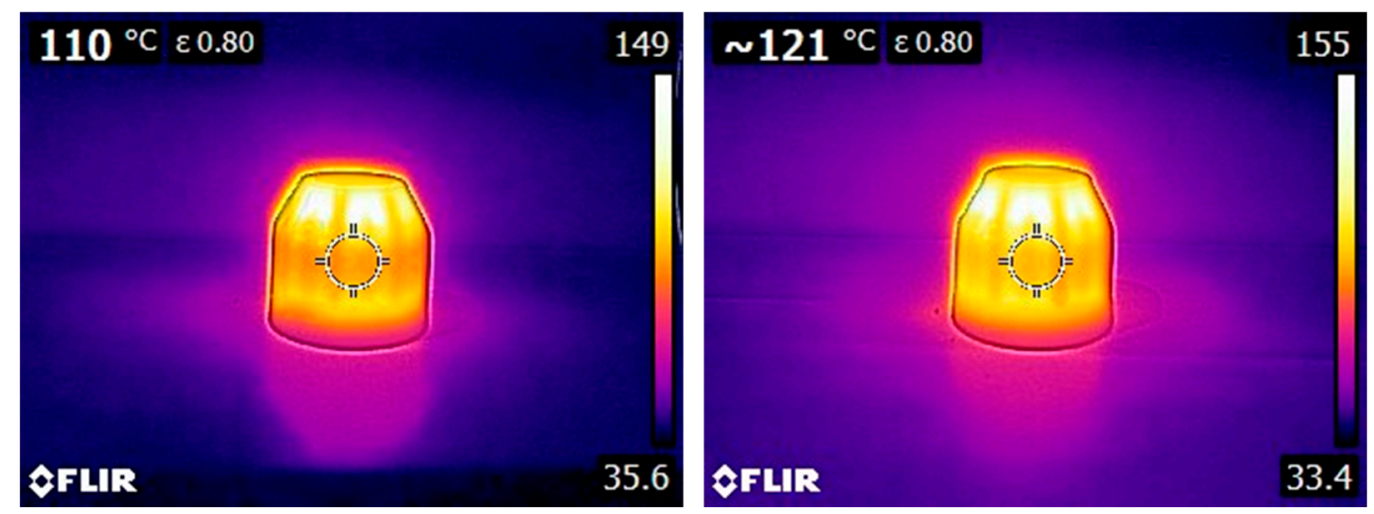

Figure 13. Cont. 


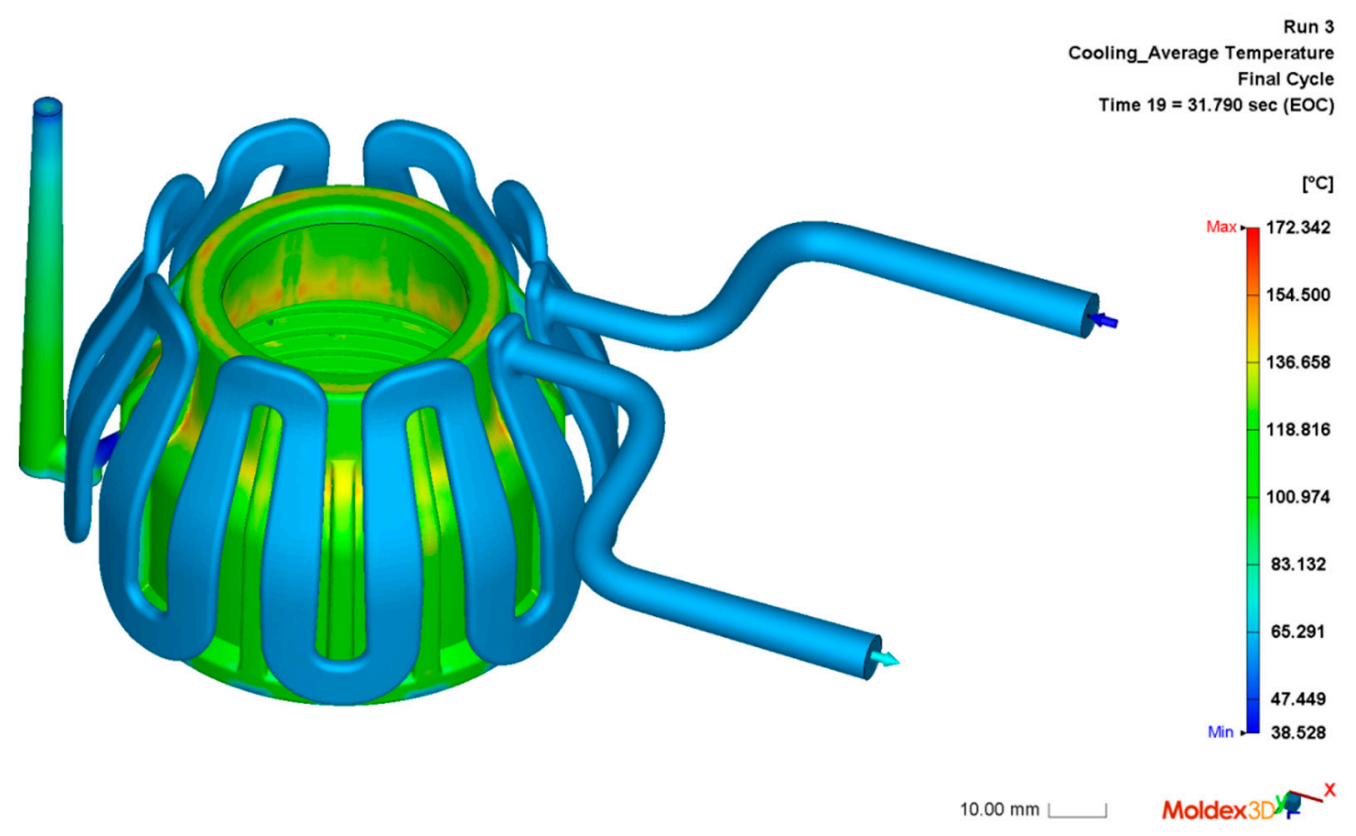

Figure 13. Temperature measurements with infrared thermal camera after ejection demonstrating the temperature reduction on the cap product when applying conformal cooling (top left) compared to conventional cooling (top right) and simulated temperatures of cap with conformal cooling by means of FEA immediately after ejection with an average temperature of the cap of $110^{\circ} \mathrm{C}$ (bottom).

\subsubsection{Results of Injection-Moulded Product Quality Improvement and Process Cycle Reduction}

The temperature reduction using conformal cooling as captured both experimentally and by means of FE computational models proved to have a positive impact on the injection-moulded product dimensional accuracy for shorter process cycles. A 3D scan of the injection-moulded product was performed and compared to the CAD model. The process cycle when using mould inserts with conformal cooling was reduced to $32 \mathrm{~s}$ compared to $47 \mathrm{~s}$ when using conventional cooling. Despite the significant cooling time reduction of $32 \%$, the product remained within production tolerances of $\pm 0.2 \mathrm{~mm}$.

Figure 14 represents the shape accuracy of the fabricated injection moulded cap and of the computed injection-moulded cap shape after cooling compared to CAD geometry. The shape deviation on the outer cap surface was limited to deviation range from of $-0.12 \mathrm{~mm}$ to $+0.04 \mathrm{~mm}$. The FEA results of the final shrunken cap shape after cooling down proved similar to the 3D scanned cap with a shape deviation range from $-0.13 \mathrm{~mm}$ to $+0.03 \mathrm{~mm}$.

An important geometrical feature of the cap, namely the shape accuracy of the inner thread, i.e., the ovality at different points, was examined as a function of cooling cycles. For this purpose, for each cooling alternative (conformal and conventional) and each cycle time (32 s, $37 \mathrm{~s}$ and $32 \mathrm{~s}$ ) 8 caps were produced and measured in terms of their inner thread ovality tolerances. Figure 15 shows the average value including standard deviation of ovality tolerance of the produced cups when using mould inserts with conformal and convectional cooling channels. An improvement of the geometrical tolerances of $72-77 \%$ was observed in the case of conformal cooling. Hereby, a nearly unchanged ovality tolerance was noticed when shortening the overall cycle time of the injection-moulding process with conformal cooling from $47 \mathrm{~s}$ to $32 \mathrm{~s}$. In contrast, an acceleration of the cycle time with conventional cooling led to a worsening of the measured geometrical tolerances with increasing ovality tolerances. A further cycle reduction of the process of under $32 \mathrm{~s}$ was not possible because shorter cycle times resulted in sink marks and warping on the cap. 


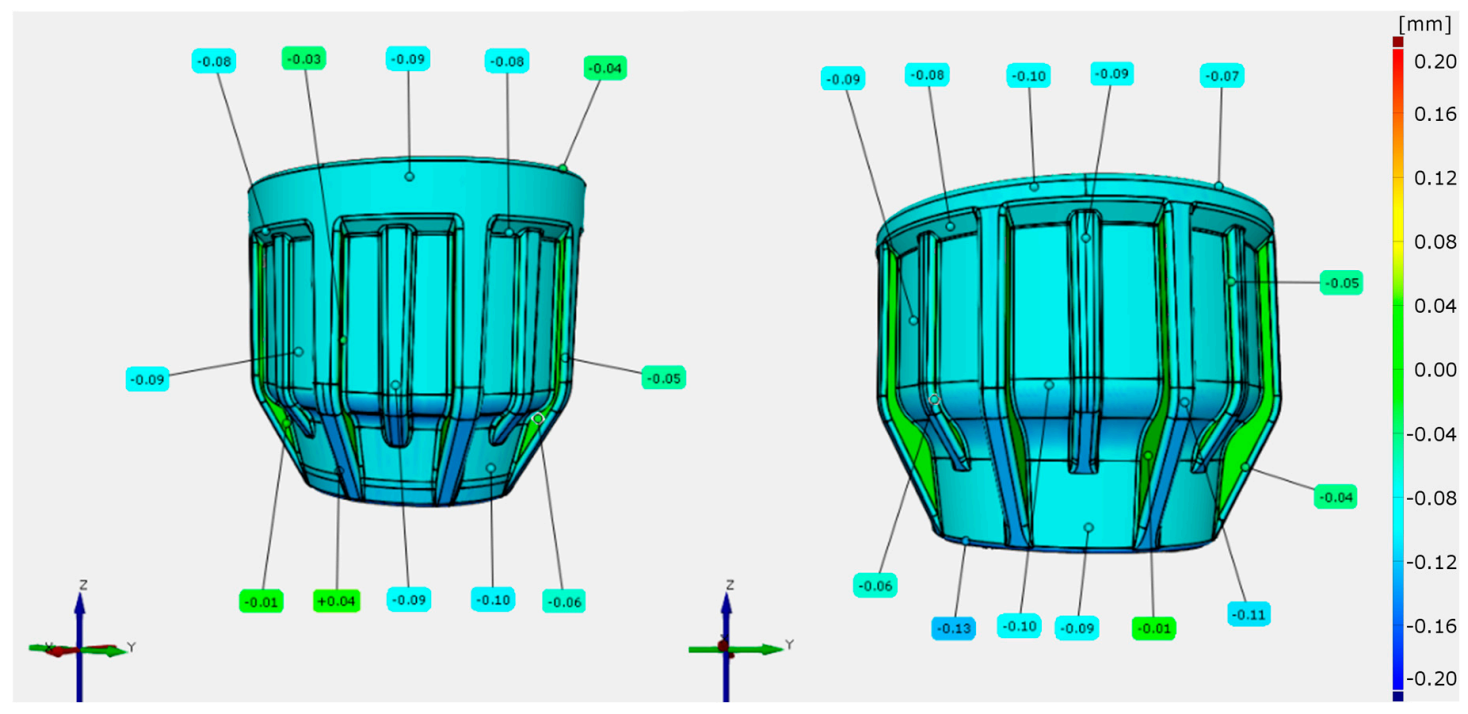

Figure 14. Shape accuracy results of the fabricated injection-moulded cap measured with the aid of a RangeVision Spectrum 3D Scanning device compared to the target CAD geometry proving the high precision when using conformal cooling (left). Final FE-simulated shrunk cap shape after cooling down compared to the target CAD geometry (right) proving similar shape deviation on the outer cap skin.

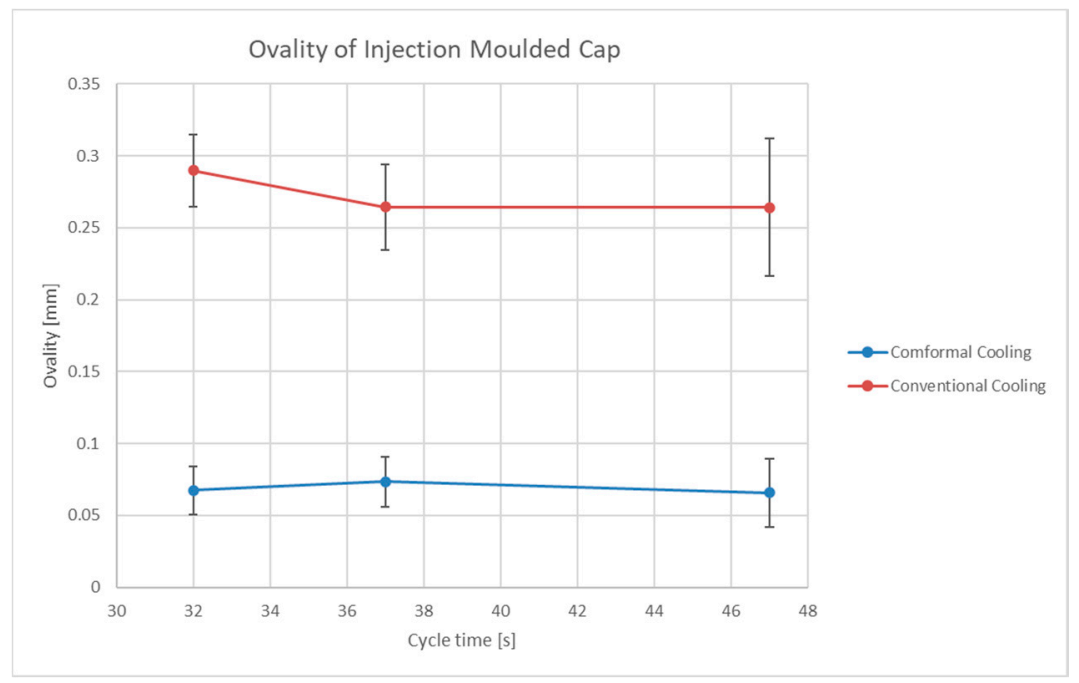

Figure 15. Unchanged ovality of inner cap threads with sinking cooling cycles when applying conformal cooling compared to overall lower dimensional accuracy and further worsening of the ovality of threads for shorter cycle time in the injection-moulding process with conventional cooling.

Finally, in order to ensure the quality of the injection-moulded caps produced by the additively manufactured mould insert with crown conformal cooling channels following additional tests were successfully performed at Elysee Irrigation Ltd.:

- dimensional inspection with the aid of gauges;

- product assembly inspection;

- pull-out creep test under axial load of $1221 \mathrm{~N}$ for $1 \mathrm{~h}$;

- hydrostatic pressure creep test at 40 bars for $1 \mathrm{~h}$; and

- bending under a pressure of 28.8 bars for $1 \mathrm{~h}$.

The fabricated caps satisfactorily demonstrated to be able to fulfill the aforementioned quality control criteria as defined by the manufacturer. 


\section{Discussion}

The results rendered in the presented research work justify the potential of conformal cooling in injection-moulding processes as described by different authors in the literature. Hereby, details are provided on the design alternatives and selection of crown conformal cooling channels based on transient thermal FE simulation results on the temperature distribution during the injection-moulding process. A temperature reduction of approximately $19 \%$ in the maximum temperature in the moulded cap was obtained when utilizing the crown conformal configuration of cooling channels over the traditional cooling. After the completion of the injection phase, the calculated temperature on the outer surface of the cap indicated a reduction of around $50 \%$ during the final stage of the cooling phase from $60{ }^{\circ} \mathrm{C}$ in case of convectional to around $30^{\circ} \mathrm{C}$ in case of conformal cooling. This behavior was also captured during the real production process by recording the temperatures in the mould insert cavity and final cap product at a time instant immediately after ejection demonstrating a temperature reduction of $14 \%$ on the cavity surface and around $9 \%$ on the cap outer surface. A continuous recording of the process temperature in the mould insert would assist in observing the cooling improvement during the whole injection mould cycle but was not realized in the frame of this work. Nevertheless, the obtained temperature reduction when utilizing conformal cooling allowed a process cycle reduction of $32 \%$ which is similar to the time reduction obtained by different other authors in the literature $[9,10,12]$. Furthermore, although the majority of authors in the literature focus on the thermal benefits and improvements related to the introduction of conformal cooling $[9,14-16,19]$, in the frame of this work a shape tolerance analysis of the final moulded product was performed alongside with the investigation of the cooling effects during injection moulding. To this end, an improvement of the geometrical tolerances was demonstrated by using conformal cooling reaching values of up $77 \%$ as measured on injection-moulded products produced in the series production line. A similar investigation on the mould product quality is presented by Ahn et al. for a fan part. [12]. Finally, although the mechanical properties of the final product produced with conformal cooling were not explicitly characterized experimentally over those produced by conventional cooling, a series of mechanical pull-out and hydrostatic creep tests as well as bending tests under pressure were conducted to ensure the quality of the final products as per the manufacturer's quality control requirements.

\section{Conclusions}

In this manuscript the adoption of crown conformal cooling channels in a mould insert fabricated by means of SLM is presented to substitute traditionally cooled mould inserts for the injection-moulding production of plastic connecting caps. In order to transfer the presented approach on different injection-moulded parts and mould inserts, a similar design approach can be applied depending on the part geometry and the associated production issues, i.e., warpage, high cooling cycle times etc. It is expected that non-cylindrical components will be more challenging to handle in terms of shape distortions. In such a case, reverse engineering operations with the aid of FE simulation should be conducted in particular, in order to define the mould insert cavity shape alongside the cooling channels configuration, so that shape distortions can be compensated and the quality of final product can be reached. It is worth mentioning that in case further polymers are to be used, a similar procedure for the selection of the injection process parameters should be applied, as described in Sections 2.1 and 3.1. The selected process parameters depend strongly on the melting temperature and melt flow rate (MFR) of the polymers. For example, in the case of polyoxymethylene (POM), also known as acetal, high mould temperatures of $60-80^{\circ} \mathrm{C}$ are to be applied, whereas in the case of polyvinylchloride (PVC), stainless steel mould inserts are to be used since this particular polymer is very corrosive. However, although the introduced method is confined to a specific product shape and thermoplastic material considering a specific steel alloy for the mould insert, in this manuscript a holistic design approach for adopting conformal cooling is elaborated. The proposed redesign of the mould insert was investigated experimentally and numerically by means of the FEA. The use of maraging 300 steel instead of the original EN 1.2343 due to absence of this material in AM proved successful since the required hardness 
was achieved. Both mould insert and moulded product provided a faster and more uniform cooling of up to $14 \%$ when compared to the original mould used for the injection-moulding process. Further tests confirmed the possibility to reduce the injection moulding cycle around $32 \%$ of the original cycle time as well as to encourage temperature reduction when using conformal cooling. Furthermore, quality requirements of the cap product such as shape tolerances were improved significantly, and creep behavior was maintained successfully. To this end, the experimental investigations and measurements were supported by computational models based on the FEA exhibiting agreeable trends. Hence, the growing importance of computational methods in supporting manufacturing process and product development was demonstrated. Finally, although the presented investigations concern a certain product of a specific material, it is considered that the adoption of the introduced cooling method in current production lines can be employed for a wider range of products in a similar manner in the near future taking into account the obtained potentials and benefits as demonstrated in this work.

Author Contributions: Conceptualization, L.P.; Data curation, L.P., S.M. and J.C.P.F.; Funding acquisition, S.A., D.P.; Investigation, L.P., S.A., D.P., S.M. and J.C.P.F.; Methodology, L.P., S.A., D.P., S.M. and J.C.P.F.; Project administration, L.P. and J.C.P.F.; Resources, L.P., S.A. and D.P.; Software, L.P., S.A. and D.P.; Supervision, L.P. and J.C.P.F.; Validation, L.P., S.A., S.M. and J.C.P.F.; Visualization, L.P., S.A. and S.M.; Writing-original draft, L.P., S.M. and J.C.P.F.; Writing - review and editing, L.P., S.A., D.P., S.M. and J.C.P.F. All authors have read and agreed to the published version of the manuscript.

Funding: This research was funded in the frame of the AMable Project by the European Commission's Horizon 2020 research and innovation program under the Grant agreement 768775. Project website: http://www.amable.eu.

Conflicts of Interest: The authors declare no conflict of interest.

\section{References}

1. Yang, L.; Hsu, K.; Baughman, B.; Godfrey, D.; Medina, F.; Menon, M.; Wiener, S. Additive Manufacturing of Metals: The Technology, Materials, Design and Production; Springer: Cham, Switzerland, 2017.

2. Parupelli, S.K.; Desai, S. Comprehensive review of additive manufacturing (3D printing): Processes, applications and future potential. Am. J. Appl. Sci. 2019, 16, 244-272. [CrossRef]

3. Schleifenbaum, H.; Diatlov, A.; Hinke, C.; Bültmann, J.; Voswinckel, H. Direct photonic production: Towards high speed additive manufacturing of individualized goods. Prod. Eng. Res. Devel. 2011, 5, 359-371. [CrossRef]

4. Schwanekamp, T.; Bräuer, M.; Reuber, M. Geometrical and topological potentialities and restrictions in selective laser sintering of customized carbide precision tools. In Proceedings of the LIM: Lasers in Manufacturing Conference, German Scientific Laser Society (WLT), Munich, Germany, 26-29 June 2017.

5. Herzog, D.; Seyda, V.; Wycisk, E.; Emmelmann, C. Additive manufacturing of metals. Acta Mater. 2016, 117, 371-392. [CrossRef]

6. Tan, C.; Zhou, K.; Ma, W.; Zhang, P.; Liu, M.; Kuang, T. Microstructural evolution, nanoprecipitation behavior and mechanical properties of selective laser melted high-performance grade 300 maraging steel. Mater. Des. 2017, 134, 23-34. [CrossRef]

7. Park, H.S.; Pham, N.H. Design of conformal cooling channels for an automotive part. Int. J. Automot. Technol. 2009, 10, 87-93. [CrossRef]

8. Kurt, M.; Kaynak, Y.; Kamber, O.S.; Mutlu, B.; Bakir, B.; Koklu, O. Influence of moulding conditions on the shrinkage and roundness of injection moulded parts. Int. J. Adv. Manuf. Technol. 2010, 46, 571-578. [CrossRef]

9. Saifullah, A.B.M.; Masood, S.H.; Sbarski, I. Thermal-structural analysis of bi-metallic conformal cooling for injection moulds. Int. J. Adv. Manuf. Technol. 2012, 62, 123-133. [CrossRef]

10. Ahn, D.G. Applications of laser assisted metal rapid tooling process to manufacture of molding \& forming tools-State of the art. Int. J. Precis. Engng. Manuf. 2011, 12, 925-938. [CrossRef]

11. Dalgarno, K.W.; Stewart, T.D. Manufacture of production injection mould tooling incorporating conformal cooling channels via indirect selective laser sintering. Proc. IMechE Part B J. Engng. Manuf. 2001, 215, 1323-1332. [CrossRef]

12. Ahn, D.G.; Park, S.H.; Kim, H.S. Manufacture of an injection mould with rapid and uniform cooling characteristics for the fan parts using a DMT process. Int. J. Precis. Engng. Manuf. 2010, 11, 915-924. [CrossRef]

13. Rännar, L.; Glad, A.; Gustafson, C. Efficient cooling with tool inserts manufactured by electron beam melting. Rapid Prototyp. J. 2007, 13, 128-135. [CrossRef] 
14. Park, H.S.; Dang, X.P. Development of a smart plastic injection mold with conformal cooling channels. Proc. Manuf. 2017, 10, 48-59. [CrossRef]

15. Abbès, B.; Abbès, F.; Abdessalam, H.; Upganlawar, A. Finite element cooling simulations of conformal cooling hybrid injection molding tools manufactured by selective laser melting. Int. J. Adv. Manuf. Technol. 2019, 103, 2515-2522. [CrossRef]

16. Torres-Alba, A.; Mercado-Colmenero, J.M.; Diaz-Perete, D.; Martin-Doñate, C. A new conformal cooling design procedure for injection moulding based on temperature clusters and multidimensional discrete models. Polymers 2020, 12, 154. [CrossRef]

17. Kuo, C.C.; Jiang, Z.F.; Lee, J.H. Effects of cooling time of moulded parts on rapid injection moulds with different layouts and surface roughness of conformal cooling channels. Int. J. Adv. Manuf. Technol. 2019, 103, 2169-2182. [CrossRef]

18. Papadakis, L.; Loizo, A.; Risse, J.; Bremen, S.; Schrage, J. A computational reduction model for appraising structural effects in selective laser melting manufacturing. Virt. Phys. Prot. 2014, 9, 17-25. [CrossRef]

19. Rosato, D.V.; Rosato, M.G. Injection Molding Handbook, 3rd ed.; Springer: New York, NY, USA, 2000.

20. Jahan, S.A.; Wu, T.; Zhang, Y.; Zhang, J.; Tovar, A.; Elmounayri, H. Thermo-mechanical design optimization of conformal cooling channels using design of experiments approach. Proc. Manuf. 2017, 10, 898-911. [CrossRef]

21. Jahan, S.A.; El-Mounayri, H. A thermomechanical analysis of conformal cooling channels in 3D printed plastic injection molds. Appl. Sci. 2018, 8, 2567. [CrossRef]

22. Cajner, F.; Landek, D.; Leskovšek, V. Surface modifications of maraging steels used in the manufacture of moulds and dies. Mater. Technol. 2010, 44, 85-91.

23. Demir, A.G.; Previtali, B. Investigation of remelting and preheating in SLM of $18 \mathrm{Ni300}$ maraging steel as corrective and preventive measures for porosity reduction. Int. J. Adv. Manuf. Technol. 2017, 93, 2697-2709. [CrossRef]

24. Mancisidor, A.M.; Gil, E.; Iturrioz, A.; Garciandia, F.; San Sebastian, M. The effect of maraging steel 300 powder characteristics in cracking susceptibility of parts manufactured by SLM. In Proceedings of the Euro PM: International Powder Metallurgy Congress and Exhibition, European Powder Metallurgy Association (EPMA), Milan, Italy, 1-5 October 2017.

25. Taufek, T.; Manurung, H.P.Y.; Lüder, S.; Graf, M.; Salleh, M.F. Distortion analysis of SLM product of SS316L using inherent strain method. In Proceedings of the IOP Conference Series: Materials Science and Engineering, 2020; Volume 834, Kota Kinabalu, Sabah, Malaysia, 14-16 August 2019. [CrossRef]

26. Setien, I.; Chiumenti, M.; van der Veen, S.; San Sebastian, M.; Garciandía, F.; Echeverría, A. Empirical methodology to determine inherent strains in additive manufacturing. Comput. Math. Appl. 2019, 2282-2295. [CrossRef]

27. Gil, E.; Mancisidor, A.M.; Iturrioz, A.; Petite, M.M.; Garciandia, F.; San Sebastian, M. Study of the heat treatment influence on the mechanical properties of SLM processed maraging 300. In Proceedings of the Euro PM 2018 Congress and Exhibition, European Powder Metallurgy Association (EPMA), Bilbao, Spain, 14-18 October 2018.

Publisher's Note: MDPI stays neutral with regard to jurisdictional claims in published maps and institutional affiliations.

(C) 2020 by the authors. Licensee MDPI, Basel, Switzerland. This article is an open access article distributed under the terms and conditions of the Creative Commons Attribution (CC BY) license (http://creativecommons.org/licenses/by/4.0/). 